Universität Bielefeld Faculty of Business Administration and Economics

Working Papers in Economics and Management

No. 12-2013

May 2013

\title{
Strategies of Foreign Direct Investment in the \\ Presence of Technological Spillovers
}

\author{
H. Dawid $\quad$ B. Zou
}




\title{
Strategies of Foreign Direct Investment in the Presence of Technological Spillovers
}

\author{
Herbert Dawid and Benteng Zou *
}

\begin{abstract}
In this paper we present a differential game model of two firms with different technologies producing the same good and selling in the same world market. The firm equipped with advanced technology is deciding whether to outsource parts of its production to the home country of its competitor, where wages and the level of technology are lower. Outsourcing reduces production costs but is associated with spillovers to the foreign competitor. The degree to which the foreign competitor can absorb these spillovers depends on its absorptive effort. Using numerical methods the properties of a Markov Perfect Equilibrium of this game are characterized and the implications of the variation of different key parameters are examined.
\end{abstract}

\section{Introduction}

Though most of the foreign direct investment (FDI) is still undertaken among the developed countries, more and more FDI flows into newly developing ones. Among the newly industrialized countries (NIC), the competition to FDI has increasingly intensified, particularly after China joined the World Trade Organization (WTO).

Herbert Dawid

Department of Business Administration and Economics and Center for Mathematical Economics, Bielefeld University, P.O. Box 100131, 33501, Bielefeld, Germany. e-mail: hdawid@wiwi.unibielefeld.de

Benteng Zou

CREA, University of Luxembourg, 162a Av. de la Faiencerie, Luxembourg. e-mail: benteng.zou@uni.lu

* Both authors acknowledge financial support from the German Science Foundation (DFG) under grant GRK1134/1: International Research Training Group 'Economic Behavior and Interaction Models (EBIM)' and the support of COST Action IS1104 "The EU in the new economic complex geography: models, tools and policy evaluation ". 
The overall picture of investment is that FDI flows into Asia more than to other developing countries in other regions, with the highest proportion of money flowing into China compared to other developing economies. FDI inflow is highly appreciated by the NIC, where the main reason are twofold: On the one side, the FDI can generate income for local firms and workers; and on the other side, the spillover effect is identified as very important for local firms and their development. Spillover here is not only transfer of production technology, management skill, marketing and ideas, but also the competitive pressure which may spur local firms to operate more efficiently or take more advanced technology( see Kokko [15]). As stated by the Global Economic Prospectus from the World Bank ([22], Page 3) “... The lack of advanced technological competencies in these countries means that technological progress in developing countries occurs through the adoption and adaptation of preexisting but new-to-the-market or new-to-the-firm technologies" and Chapter 3 of this report identifies a number of important and policy-relevant trends and explores some policy implications.

Although the empirical evidence concerning the existence of positive horizontal spill-overs from FDI is mixed, there exists evidence that FDI is associated with positive spill-overs, (see e.g. Görg and Greenaway [11]). Indeed, recent empirical studies find positive horizontal spillovers from FDI using firm level data from Hungary (Halpern and Murakozy [13]), Romania (Smarzynska and Spatareanu [19]), from 17 emerging market economies (Gorodnichenko et al. [12]). From Chinese manufacturing firms, Liu [16] addresses both short-run negative productivity effects and long-run positive effect of domestic firm due to FDI, and from Lithuania, Javorcik [9] produces evidence consistent with positive productivity spillovers from FDI taking place through contacts between foreign affiliates and their local suppliers in upstream sectors. Several channels of spill-overs have been discussed in the literature, most prominently the demonstration effect, labor turnover (both inducing horizontal spill-overs), and vertical linkages (see e.g. Saggi [18]), among others.

In order to generate positive technological transfers to local firms based on FDI, the receiving country must have appropriate institutions in place and local firms must be ready to adopt new technologies and to adapt their behavior. As has been discussed extensively in the literature on 'absorptive capacity' (see e.g. Cohen and Levinthal [1], local firms have to invest effort in order to build up their capacity to digest information and knowledge that might spill over from more advanced firms investing in their country and to generate productivity increases. The incentives to invest such efforts are driven by the expectations of the firms with respect to future spillovers they might receive and the economic implications of such incoming spillovers. Hence, the determination of absorptive effort should be based on intertemporal considerations of the local firms.

Similarly, the firms with advanced technology are aware that their activities in foreign countries may yield a technological improvement of their foreign competitors jeopardizing in the long-run their technological advantage. 
Taking the above two sides story into consideration, a differential game is presented in which a firm with advanced technology makes the decision of whether to outsource parts of its production to a less developed economy where wages and the level of technology are lower. A firm in the less advanced economy decides how much effect to make to absorb the potential spillover. In our setting, the advanced technology taken by the FDI is fixed and hence catching up in technology is possible, which comes from the idea also mentioned in the report of World Bank [22] that "The level of technological achievement in developing countries has converged with that of high-income countries over the past 15 years".

Following some FDI literature, such as, Das[3]), Wang and Blomstrom [21], Dawid et al [4], among others, we assume that the change in the host country's productivity is formulated as an increasing function of the presence of foreign capital stock.

The consideration of the dynamic strategic interplay between FDI decisions and the choice of investments in absorptive capacity gives rise to a differential game with a two-dimensional state space and state dynamics characterized by interaction terms of both states and a control. We are interested in characterizing a Markovperfect equilibrium (MPE) of this game. Closed form solutions for MPE strategies are however available only for a small set class of differential game, most prominently linear quadratic games. The game considered here does not fall in any of these classes and therefore we rely on numerical methods to characterize MPEs, the induced investment paths as well as their dependence on parameters and initial conditions. In particular, we use collocation methods employing a Chebychev polynomial basis to approximate a solution to the set of Hamilton-Jacobi-Bellman equations characterizing the MPE. A similar technique has been used to study MPEs of non-linear quadratic differentical games for exmaple in Vedenov and Miranda [20], Doraszelski [6] and Dockner and Mosburger [5]. ${ }^{2}$

The rest of the paper is organized as follows. In the next section, we present the model. In Section 3, we derive conditions characterizing a Markov-perfect equilibrium and describe our numerical approach. The results of our equilibrium analysis are presented and discussed in Section 4 and Section 5 concludes.

\section{The model}

We consider a dynamic two-country model where country $\mathrm{H}$ ('home country') is a developed industrialized country whereas country F ('foreign country') is a newly industrializing country. For simplicity we consider only a singe firm in each country

\footnotetext{
${ }^{2}$ See Judd [14] or Miranda and Fackler [17] for a more general treatment of collocation methods for dynamic optimization and the survey of Jorgensen and Zaccour [10] for more information as to using numerical methods to solve differential games.
} 
and we denote by $Q_{i}(t)$ the output of firm $i$ at time $t, i=H, F$. The two firms compete on a common market characterized by an inverse demand function $P\left(Q_{H}+Q_{F}\right)$, where at each point in time both firms simultaneously choose their output quantities.

Firms produce using labor as the only variable production input. Production capacities of a firm in a country are determined by its capital stock there. For simplicity it is assumed that both firms have sufficiently large production capacities in the their home country to be able to produce the desired output. However, the production of firm $H$ in country $F$ is constrained by the size of the foreign capital stock firm $H$ has accumulated in that country. Output per input unit in the two countries is given by $A_{H}(t)$ and $A_{F}(t)$ with $A_{H}(t)>A_{F}(t)$. If a firm from country $\mathrm{H}$ produces in country $F$, productivity reads $A_{H F}(t)$ where $A_{F}(0)<A_{H F}(0)<A_{H}(0)$. Since our focus is on the effects of technological spill-overs generated by FDI on the evolution of the technology gap between the two countries, we abstract from technological change in the developed country and assume that $A_{H}$ and $A_{H F}$ are constant over time, whereas $A_{F}(t)$ may change over time due to spill-over effects. In both countries labor is supplied at wage rates $w_{H}$ and $w_{F}$, where $w_{H}>>w_{F}$. It is assumed that wages stay constant over time. In particular with respect to country $F$, where productivity might increase over time due to spillovers, this assumption is debatable, however the qualitative features of the model would not change if it would be assumed that wages go up due to productivity increases as long as the wages change at a lower rate than productivity such that the spill-overs induce a reduction in unit costs for firms in country $F$. Assuming constant wages, substantially simplifies the analysis compared to such a setting.

We assume that the firm in country $H$ can reduce its unit production costs if it produces in the foreign country, i.e.

$$
\frac{w_{H}}{A_{H}}>\frac{w_{F}}{A_{H F}} .
$$

In order to produce abroad, firm $H$ has to invest to build up production capacities in country $F$. We denote by $I(t) \in \mathscr{R}$ foreign investment of firm $H$ and by $K_{F}(t)$ the capital stock of firm $H$ in country $F$ at time $t$. It should be noted that we also allow for negative investment, and due to the spillover-effects described below disinvestment might in principle be optimal for firm $H$. The capital accumulation equation is given by

$$
\dot{K}_{F}(t)=I(t)-\delta K_{F}(t)
$$

where $\delta$ is the depreciation rate of capital and $I \in \mathbb{R}$.

Foreign direct investments of country $H$ firm in country $\mathrm{F}$ generates technological spill-overs. Following Findlay[8], Wang and Blomstrom [21] and Dawid et al [4], we posit that the change in technology level in the foreign country is given by

$$
\dot{A}_{F}(t)=\lambda(t) K_{F}(t)\left(A_{H F}-A_{F}(t)\right) .
$$


The speed of absorption is determined by the absorption rate $\lambda$ which is assumed to be

$$
\lambda(t)=a+b \alpha(t),
$$

with $a \geq 0, b \geq 0$ and $\alpha(t) \in \mathbb{R}_{+}$denotes the effort of Firm $F$ in order to absorb knowledge brought into country $F$ by the FDI of firm $H$. Notice that we allow also for the case, if $a>0$, where spillovers are positive even if the absorptive effort of firm $F$ is $\alpha=0$. However, with effort of firm $F$, it will speed up the catching up process. On the other hand, for $a=0$, which we will consider as the default case, there is no absorption of knowledge of firm $F$ unless it invests positive effort.

In addition to investment (for firm $H$ ) and absorptive effort (for firm $F$ ), both firms at each point in time also choose their output quantities. However, since the output choices do not have any intertemporal implications, it is obvious that the quantities are chosen according to Cournot equilibrium with marginal $\operatorname{costs} c_{H}=$ $\frac{w_{H}}{A_{H}}, c_{F}(t)=\frac{w_{F}}{A_{F}(t)}$. It should be noted that using these marginal costs we assume that firm $H$ is not able to produce its entire output with its foreign capital stock in country $F$. We have verified that this assumption holds in the equilibrium we calculate in the next section.

In the following, we assume a linear inverse demand function given by

$$
P(t)=\bar{P}-\left(Q_{H}(t)+Q_{F}(t)\right)
$$

where $\bar{P}>0$ is the reservation price. Then, the equilibrium outputs and profits in the oligopoly market are given as follows ${ }^{3}$, where we write these expressions as functions of the state $A_{F}(t)$ :

$$
\begin{aligned}
Q_{H}^{*}\left(A_{F}\right) & =\frac{\bar{P}-2 \frac{w_{H}}{A_{H}}+\frac{w_{F}}{A_{F}}}{3}, Q_{F}^{*}\left(A_{F}\right)=\frac{\bar{P}-2 \frac{w_{F}}{A_{F}}+\frac{w_{H}}{A_{H}}}{3}, \\
\Pi_{H}^{*}\left(K_{F}, A_{F}\right) & =\left(Q_{H}^{*}\left(A_{F}\right)\right)^{2}+K_{F} A_{H F}\left(\frac{w_{H}}{A_{H}}-\frac{w_{F}}{A_{H F}}\right) \\
\Pi_{F}^{*}\left(A_{F}\right) & =\left(Q_{F}^{*}\left(A_{F}\right)\right)^{2} .
\end{aligned}
$$

Inserting these expressions into the objective functions of both firms allows us to consider only the intertemporally relevant controls $I$ and $\alpha$ when formulating the maximization problems of the firms.

Firm H's objective then is to choose its investment strategy in order to maximize its discounted payoff stream given by

\footnotetext{
${ }^{3}$ See Dawid et al. [4] for detailed calculations.
} 


$$
\max _{I(.)} J_{H}=\int_{0}^{\infty} e^{-r t}\left[\Pi_{H}^{*}\left(K_{F}, A_{F}\right)-\left(\beta_{H} I+\gamma_{H} I^{2}\right)\right] d t,
$$

where firm H's market profit $\Pi_{H}^{*}$ is given by (5)). Firm F's problem is to choose its effort strategy, $\alpha$, to maximize its present value

$$
\max _{\alpha(.)} J_{F}=\int_{0}^{\infty} e^{-r t}\left[\Pi_{F}^{*}\left(A_{F}\right)-\left(\beta_{F} \alpha+\gamma_{F} \alpha^{2}\right)\right] d t,
$$

with market profit $\Pi_{F}^{*}\left(A_{F}\right)$ given by (6). The optimization problems are subject to the state dynamics (2), (3) and the initial conditions

$$
K_{F}(0)=0, A_{F}(0)=A_{F}^{i n i} \in\left(0, A_{H F}\right) .
$$

\section{Markov-Perfect Equilibria}

Our analysis is based on the consideration of Markov-perfect equilibria of the game described in the previous section. Given that both firms have infinite planing horizons and time-autonomous instantaneous objective functions, we assume that firms use stationary Markovian feedback strategies of the form $I\left(K_{F}, A_{F}\right): X \mapsto \mathbb{R}$ (for firm $H$ ) and $\alpha\left(K_{F}, A_{F}\right): X \mapsto \mathbb{R}_{+}$(for firm $F$ ), where $X=[0, \bar{K}] \times\left[\underline{A}, A_{H F}\right]$ is the considered state space with $\bar{K}$ sufficiently large and $\underline{A}$ smaller than $A_{F}^{i n i}$. A pair of strategies $\left(I^{*}, \alpha^{*}\right)$ is a Markov-perfect equilibrium if for each firm its feedback strategy induces a control path which solves the dynamic optimization problem (7) respectively $V^{F}\left(K_{F}, A_{F}\right)$ given that the opponent sticks to its equilibrium feedback strategy. It is well known that Markov perfect equilibria are strongly time consistent (see Dockner et al. [2])) and hence this is the standard concept for the characterization of the dynamic strategic interaction of firms which are not able to commit ex-ante to certain control paths.

Due to the time autonomous nature of the objective and the infinite time horizon also the value functions of both firms in a (stationary) MPE do not explicitly depend on $t$ and can be written as $V^{H}\left(K_{F}, A_{F}\right)$ respectively $V^{F}\left(K_{F}, A_{F}\right)$. The value functions of firm $h$ has to solve the following Hamilton-Jacob-Bellman (HJB) equation

$$
\begin{aligned}
r V^{H} & =\max _{I \in \mathbb{R}}\left\{\left[\Pi_{H}\left(K_{F}, A_{F}\right)-\left(\beta_{H} I+\gamma_{H} I^{2}\right)\right]\right. \\
& \left.+\left[V_{K_{F}}^{H}\left(I-\delta K_{F}\right)+V_{A_{F}}^{H}\left(a+b \alpha^{*}\left(K_{F}, A_{H F}\right)\right) K_{F}\left(A_{H F}-A_{F}\right)\right]\right\}
\end{aligned}
$$

where $V_{K_{F}}^{H}\left(V_{A_{F}}^{H}\right)$ represents the partial derivative of $V^{H}$ with respect to $K_{F}\left(A_{F}\right)$.

Since the right hand side of the above HJB equation is strictly concave with respect to $I$, the first order condition is necessary and sufficient for maximization problem, which gives 


$$
I^{*}=\frac{V_{K_{F}}^{H}-\beta_{H}}{2 \gamma_{H}} .
$$

Similarly, the value function of firm $F$ solves the HJB equation

$$
\begin{aligned}
r V^{F} & =\max _{\alpha \in \mathbb{R}_{+}}\left\{\left[\Pi_{F}\left(A_{F}\right)-\left(\beta_{F} \alpha+\gamma_{F} \alpha^{2}\right)\right]\right. \\
& \left.+\left[V_{K_{F}}^{F}\left(I^{*}\left(K_{F}, A_{F}\right)-\delta K_{F}\right)+V_{A_{F}}^{F}(a+b \alpha) K_{F}\left(A_{H F}-A_{F}\right)\right]\right\}
\end{aligned}
$$

and the optimal effort is

$$
\alpha^{*}=\frac{\max \left[b V_{A_{F}}^{F} K_{F}\left(A_{H F}-A_{F}\right)-\beta_{F}, 0\right]}{2 \gamma_{F}} .
$$

Substituting the optimal choice (10) and (12) into the HJB equations (9) and (11), we obtain the two Bellman equation system

$$
\begin{aligned}
& r V^{H}-\Pi_{H}\left(A_{F}, K_{F}\right)+\frac{\beta_{H}\left(V_{K_{F}}^{H}-\beta_{H}\right)}{2 \gamma_{H}}+\frac{\left(V_{K_{F}}^{H}-\beta_{H}\right)^{2}}{4 \gamma_{H}}-V_{K_{F}}^{H}\left(\frac{V_{K_{F}}^{H}-\beta_{H}}{2 \gamma_{H}}-\delta K_{F}\right) \\
& -V_{A_{F}}^{H}\left[a+b\left(\frac{\max \left[b V_{A_{F}}^{F} K_{F}\left(A_{H F}-A_{F}\right)-\beta_{F}, 0\right]}{2 \gamma_{F}}\right)\right] K_{F}\left(A_{H F}-A_{F}\right)=0
\end{aligned}
$$

and

$$
\begin{aligned}
& r V^{F}-\Pi^{F}\left(A_{F}, K_{F}\right)+\frac{\beta_{F} \max \left[b V_{A_{F}}^{F} K_{F}\left(A_{H F}-A_{F}\right)-\beta_{F}, 0\right]}{2 \gamma_{F}} \\
& +\frac{\max \left[b V_{A_{F}}^{F} K_{F}\left(A_{H F}-A_{F}\right)-\beta_{F}, 0\right]^{2}}{4 \gamma_{F}}-V_{K_{F}}^{F}\left(\frac{V_{K_{F}}^{H}-\beta_{H}}{2 \gamma_{H}}-\delta K_{F}\right) \\
& -V_{A_{F}}^{F}\left[a+b\left(\frac{\max \left[b V_{A_{F}}^{F} K_{F}\left(A_{H F}-A_{F}\right)-\beta_{F}, 0\right]}{2 \gamma_{F}}\right)\right] K_{F}\left(A_{H F}-A_{F}\right)=0 .
\end{aligned}
$$

Any pair of value functions satisfying (13), (14) and the transversality conditions

$$
\lim _{t \rightarrow \infty} e^{-r t} V^{H}\left(K_{F}^{*}(t), A_{F}^{*}(t)\right)=\lim _{t \rightarrow \infty} e^{-r t} V^{F}\left(K_{F}^{*}(t), A_{F}^{*}(t)\right)=0,
$$

where $\left(K_{F}^{*}(t), A_{F}^{*}(t)\right)$ denotes the state trajectory induced by the pair of value functions corresponds to a Markov-perfect equilibrium of the game. Due to the nonlinear structure of the system of partial differential equations (13), (14) no closed form solutions can be obtained. Therefore, we numerically determine a pair of value functions that approximately solves (13), (14) on the state space $X$ and calculate approximations of the equilibrium feedback strategies using these value function approximations. We briefly describe the procedure in the following subsection. 


\subsection{Numerical Approach}

We employ a collocation method using Chebychev polynomials to obtain the approximation of the value functions and the equilibrium feedback strategies. To this end we generate a set of $n_{K}$ Chebychev nodes $\mathscr{N}_{\mathscr{K}_{\mathscr{F}}}$ in $[0, \bar{K}]$ and a set of $n_{A}$ Chebychev nodes $\mathscr{N}_{\mathscr{A}_{\mathscr{F}}}$ in the interval $\left[\underline{A}, A_{H F}\right]$ (see e.g. Judd [14] for the definition of Chebychev nodes and Chebychev polynomials) and define the set of interpolation node in the state space $X$ as

$$
\mathscr{N}=\left\{\left(k_{f}, a_{f}\right) \mid k_{f} \in \mathscr{N}_{\mathscr{K}_{\mathscr{F}}}, a_{f} \in \mathscr{N}_{\mathscr{A}_{\mathscr{F}}}\right\}
$$

Note that the cardinality of $\mathscr{N}$ is $n_{K} n_{A}$. In what follows we calculate polynomial approximations of $V^{H}$ and $V^{F}$ which satisfy (13) and (14) on the set of interpolation nodes $\mathscr{N}$. It is well known that the choice of Chebychev interpolation nodes avoids large oscillations of the interpolating polynomial between the interpolation node (as could occur e.g. for equi-distant nodes) and implies that the interpolating polynomials approximately solve the HJB equations on the entire state space.

The set of basis functions for the polynomial approximation is determined as $\mathscr{B}=\left\{B_{j, k}, j=1, . ., n_{K}, k=1, . ., n_{A}\right\}$ with

$$
B_{j, k}\left(K_{F}, A_{F}\right)=T_{j-1}\left(-1+\frac{2 K_{F}}{\bar{K}_{F}}\right) T_{k-1}\left(-1+\frac{2\left(A_{F}-\underline{A}\right)}{\left(A_{H F}-\underline{A}\right)}\right),
$$

where $T_{j}(x)$ denotes the $j$-the Chebychev polynomial (see e.g. Judd [14] for the definition of the Chebychev polynomial basis). Since Chebychev polynomials are defined on $[-1,1]$ the state variables have to be transformed in the way shown above.

The value function is approximated by

$$
V^{i}\left(K_{F}, A_{F}\right) \approx \hat{V}^{i}\left(K_{F}, A_{F}\right)=\sum_{j=1}^{n_{K}} \sum_{k=1}^{n_{A}} C_{j, k}^{i} B_{j, k}\left(K_{F}, A_{F}\right),\left(K_{F}, A_{F}\right) \in X, i=H, F
$$

where $C=\left\{C_{j, k}^{i}\right\}$ with $j=1, \cdots, n_{K}, k=1, \cdots, n_{A}, i=H, F$ is the set of $2 n_{K} n_{A}$ coefficients to be determined.

To determine these coefficients we set up a system of non-linear equations derived from the condition that $\left(\hat{V}^{H}, \hat{V}^{F}\right)$ satisfies the HJB equations (13) and (14) on the set of interpolation nodes $\mathscr{N}$. This system consists of $2 n_{K} n_{A}$ equations with $2 n_{K} n_{A}$ unknowns (i.e. the coefficients $C_{j, k}^{i}$ ) and is solved by a recursive algorithm, where based on an initial guess $\tilde{C}^{0}=\left\{C_{j, k}^{i, 0}, j=1, . ., n_{K}, k=1, . ., n_{A}, i=H, F\right\}$ of the coefficients in iteration $l \geq 1$ the coefficients $\tilde{C}^{l-1}$ are used to calculate approximations of the value functions and their partial derivatives at each node in $\mathscr{N}$. These approximations are inserted for all terms that occur in (13) and (14) where the value functions or their derivatives appear in a non-linear form. Inserting the approximation (15) with $C$ replaced by $\tilde{C}^{l}$ for all terms in (13) and (14) where the 
value functions and their derivatives occur in a linear way, yields a linear system of equations for the coefficients $\tilde{C}^{l}$, which even for large values of $2 n_{K} n_{A}$ can be solved efficiently using standard methods as long as the coefficient matrix is well conditioned. The solution of this linear system gives the new set of coefficient values $\tilde{C}^{l}$. To complete the iteration the new approximations of the value functions and their derivatives are inserted into all (including the non-linear) corresponding terms in (13) and (14) and the resulting absolute value of the left hand side of these equations relative to the corresponding value function is determined for all nodes in $\mathscr{N}$. If the maximum of this relative error is below a given threshold $\varepsilon$ the algorithm is stopped, we set $C=\tilde{C}^{l}$ and the current approximation of the value functions is used to calculate the feedback strategies of the players and the equilibrium dynamics.

Unfortunately, no general conditions can be given that guarantee the existence of a stable fixed point of the described algorithm, which corresponds to an economically meaningful Markov-perfect equilibrium of the game. Also, starting with an appropriate initial guess for the coefficients is often crucial for convergence to a meaningful fixed point, even if there exists such a stable fixed point. To obtain the numerical results discussed in the next section a continuation method was applied by starting with a simplified problem without strategic interaction $(a=b=0)$ and then increasing the variable $b$ in small steps to arrive at the default parameter setting with $b=0.2$ (see below), where in each step the value function approximations from the previous steps are used as the initial guess for the current step. Similar methods were used to obtain results for the different parameter variations reported below.

For all numerical solutions reported it was checked that the state dynamics under the equilibrium strategies does not leave $X$ for any initial conditions in $X$, which implies that the considered state space is sufficiently large to allow the correct calculation of the value functions under the considered equilibria and also implies that the transversality conditions are satisfied.

\section{Results}

The results presented below are based on the default parameter setting given in Table 4 which to a large extend follows the values used in Dawid et al. [4]). These values are not based on a serious empirical calibration of the model, but, by sticking to the parametrization in Dawid et al. [4] allows us to highlight the implication of the consideration of dynamic strategic interaction between the firms in the two countries, which was not considered in that paper. The ratio of wages in the two countries is four to one, and the monetary unit is normalized in a way that the wage in country $\mathrm{F}$ is $w_{F}=1$. Unit costs of production for firm $H$ in country $F\left(w_{F} / A_{H F}=\right.$ $0.5)$ are well below the unit costs at home $\left(w_{H} / A_{H}=1\right)$.

The upper bound for the foreign capital stock of firm $H$ is set to $\bar{K}=0.6$, which under the considered cost parameters is sufficient to ensure that firm $H$ never has 
incentives to build a stock larger than $\bar{K}$. Also, by setting $A_{H F}=2$ and $\underline{A}=1.5$, we restrict attention to the case where the initial productivity in country $F$ is relatively close to $A_{H F}$, which in the absence of the consideration of absorptive effort choice always leads to a convergence of productivity in country $F$ to $A_{H F}$. The robustness of the qualitative findings reported below with respect to variations in this parameter setting has been tested.

$$
\begin{array}{lccc}
A_{H}=4 & A_{H F}=2 & w_{H}=4 & w_{F}=1 \\
\beta_{H}=0 & \gamma_{H}=250 & \beta_{F}=0 & \gamma_{F}=0.03 \\
\delta=0.06 & r=0.03 & \bar{P}=5 & \\
a=0 & b=0.2 & \\
\bar{K}=0.6 & \underline{A}_{F}=1.5 & K^{i n i}=0 & A_{F}^{i n i}=1.55 \\
n_{K}=8 & n_{A}=8 & \varepsilon=0.003
\end{array}
$$

Table 1 Standard parameter setting

Figure 1 shows the feedback strategies of the two firms in the MPE under the default parameter setting. The qualitative features of these feedback strategies are quite intuitive. The foreign investment of firm $H$ becomes smaller the larger the technological gap of firm $F$ is because the lager the gap the larger the marginal effect of an additional unit of foreign capital on the future increase in $A_{F}$. This increase reduces marginal costs of firm $F$, which negatively affects the future profits of firm $H$. Furthermore, investments are an increasing function of the stock of foreign capital firm $H$ has. The reason for this observation is similar to that just given with respect to changes in $A_{F}$. The larger foreign capital stock of firm $H$ the faster the productivity of firm $F$ will catch-up and the smaller will be the technology gaps in the future. Smaller future technology gaps imply that the negative future effects of an additional unit of foreign capital for firm $H$ are smaller and hence investments of that firm increase. Absorptive effort of firm $F$ is larger the larger the capital stock $K_{F}$ is because the marginal effect of absorptive effort grows with $K_{F}$. On the other hand, the marginal effect of absorptive effort declines as $A_{F}$ comes closer to $A_{H F}$ and therefore effort is a decreasing function of $A_{F}$.

Figure 2 shows the dynamics of the state and control variables in the MPE for the default parameter setting and an initial productivity of firm $F$ of $A_{F}(0)=1.55$. It can be clearly seen that under the default setting firm $H$ builds up a positive capital stock in country $F$ and keeps a positive stock in the long run. Firm $F$ chooses positive absorption effort throughout the run and is therefore able to completely close the gap between its own productivity $A_{F}$ and the productivity $A_{H F}$ of the high-tech firm $H$ when producing in country $F$. The amount of effort invested in absorption is nonmonotone with a steep initial increase in effort and a long phase of decreasing effort after an early peak at approximately $t=15$. The intuition for the non-monotone dynamics of the absorptive effort is that the marginal effect of an increase of $K_{F}$ on 




(a)



(b)

Fig. 1 Equilibrium strategies of firms $H$ (a) and firm $F$ (b) for the default parameter setting.

the incentives to invest in absorptive effort is large in the initial periods when the technological gap is still large. The fast catch-up of $A_{F}$ towards $A_{H F}$ reduces the marginal future value of an investment in absorptive effort and therefore reduces the incentives for firm $F$ to choose a high $\alpha$. This effect starts to dominate after $t=15$ inducing a steady decline in $\alpha$. However, the absorptive effort always stays positive because under the default parameter setting marginal costs of effort converge to zero as $\alpha$ becomes small. As we will see below the property that marginal costs of effort are zero for $\alpha=0$ is the crucial property that induces a full catch-up steady state.

In order to understand the implications of a relaxation of the assumption that marginal costs of effort are zero at $\alpha=0$ we now consider the effects of an increase of the parameter $\beta_{F}$. For positive $\beta_{F}$ marginal costs of effort are strictly positive on the entire control space $\mathbb{R}_{+}$. In Figure 3 we show the feedback functions in the MPE for $\beta_{F}=0.2$. Setting $\beta_{F}$ to that positive value induces that $\alpha=0$ on a substantial part of the state space. In particular, for small foreign capital stocks of firm $H$ and for a small technological gap, the marginal (present and future) returns of absorptive effort are not sufficient to outweigh the marginal costs and therefore firm $F$ does not invest any effort to absorb the potential spillovers from firm $H$. In equilibrium firm $H$ takes this behavior of its opponent into account and therefore reduces investment in the areas of the state space close to the line where firm $F$ starts to invest positive effort. In the interior of the region where firm $F$ invests positive effort the same logic as in the case of $\beta_{F}=0$ implies that investment of firm $H$ is an increasing function of $K_{F}$ and this gives rise to the rather complex and non-monotone shape of the feedback function of firm $H$.

The implications of these changes in the feedback strategies on the equilibrium dynamics of states and controls can be seen in Figure 4. First, considering the dynamics of $K_{F}$ and $A_{F}$ we observe that no full catch-up of the productivity of firm $F$ emerges although firm $H$ keeps a positive foreign capital stock in the long-run. Hence, contrary to the case with exogenous absorptive capacity studied in Dawid et al. [4] with endogenous absorptive capacity a steady state exists where the high tech firm $H$ can keep some productivity advantage relative to its local competitor 


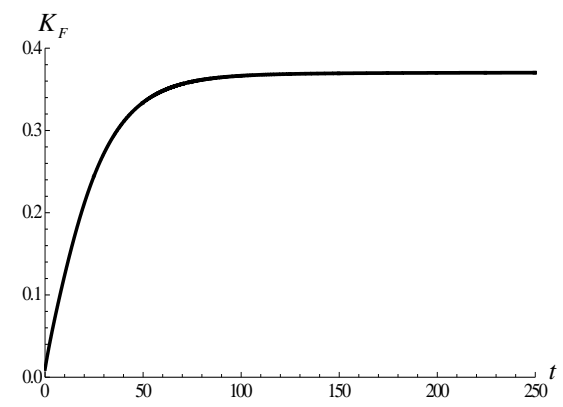

(a)

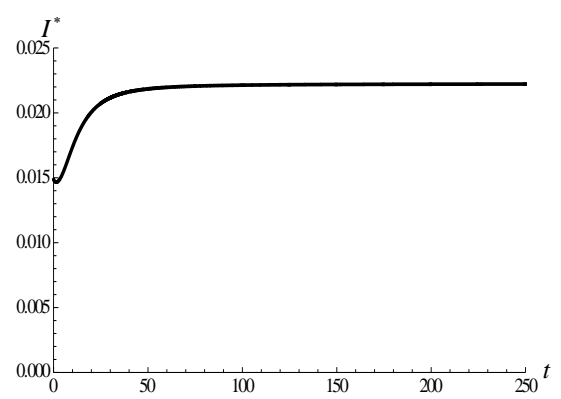

(c)



(b)

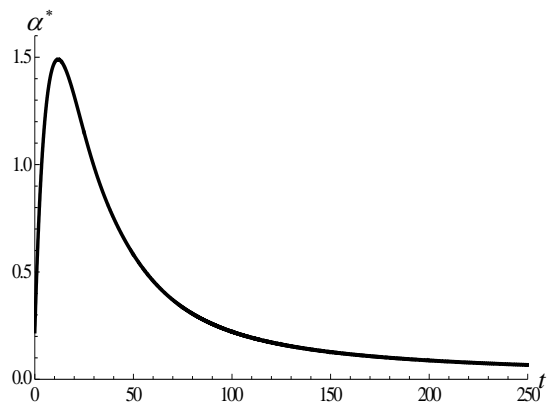

(d)

Fig. 2 Equilibrium dynamics under the default parameter setting: (a) foreign capital stock of firm $H$, (b) productivity of firm $F$, (c) investment of firm $H$, (d) absorptive effort of firm $F$.

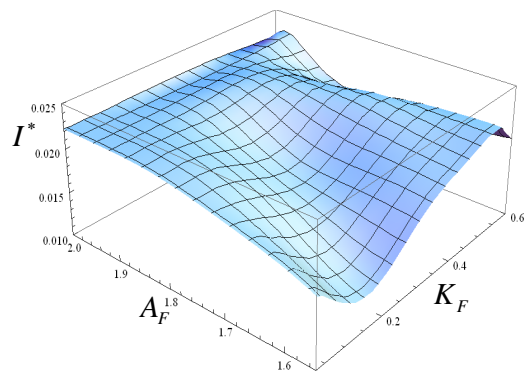

(a)

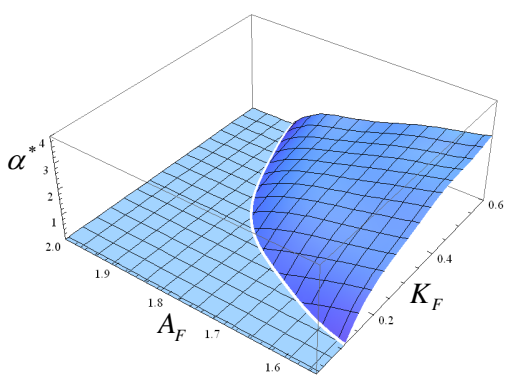

(b)

Fig. 3 Equilibrium feedback strategies of firms $H$ (a) and firm $F$ (b) for $\beta_{F}=0.2$. 
in country $F$ although it keeps exploiting the wage advantage in country $F$ with a positive long run stock of foreign capital. Whereas the steady state level of the productivity of firm $F$ is a strictly decreasing function of $\beta_{F}$ the dependence of the size of the long run foreign capital stock of firm $H$ from $\beta_{F}$ is non-monotonous, where this level is approximately identical for $\beta_{F}=0$ and $\beta_{F}=0.2$, but substantially smaller for $\beta_{F}=0.1$. In the initial part of the dynamics a larger value of the absorptive cost parameter $\beta_{F}$ induces a smaller foreign capital stock of firm $H$. This might seem counter-intuitive, but can be well explained by considering the dynamics of the controls of the two firms.

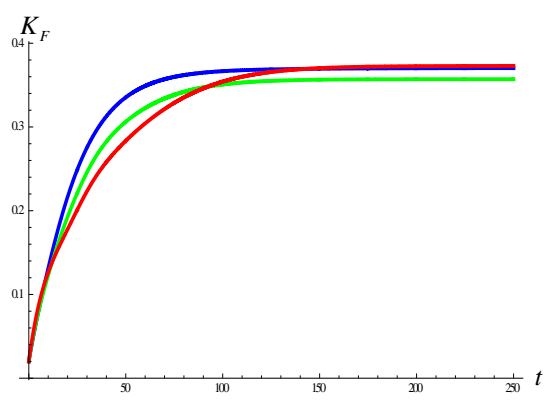

(a)



(c)



(b)



(d)

Fig. 4 Equilibrium dynamics for $\beta_{F}=0$ (blue line), $\beta_{F}=0.1$ (green line) and $\beta_{F}=0.2$ (red line): (a) foreign capital stock of firm $H$, (b) productivity of firm $F$, (c) investment of firm $H$, (d) absorptive effort of firm $F$.

For positive $\beta_{F}$ in the initial periods the stock of foreign capital is so small that firm $F$ does not invest any absorptive effort and hence the technological gap remains unchanged. Firm $H$ however foresees that due to the increase in $K_{F}$ eventually the point in time will be reached where firm $F$ starts investing absorptive effort and the productivity of firm $F$ starts to increase. As this point in time comes closer the implicit (discounted future) costs associated with an additional unit of capital in country $F$ becomes larger and therefore investment of firm $H$ decreases in the initial periods. The time interval on which investment is decreasing is longer the larger 
absorption costs $\beta_{F}$ are and this explains why an increase of absorption costs has a negative impact on the size of the foreign capital stock in the initial periods. Once firm $F$ starts choosing positive $\alpha$ the technological gap shrinks and this reduces the costs for firm $H$ of an additional unit of foreign capital due to future technological catch-up. Once this effect becomes dominant firm $H$ starts to increase its investment and firm $F$ reduces its absorptive effort until a steady state is reached where absorptive effort is again zero. It should be noted that this steady state is located exactly at the line in the state-space where the equilibrium feedback function of firm $F$ switches from zero to positive $\alpha$.

We now consider the effect of an increase of the wage in country $F$ on the dynamic of FDI and of the technological catch-up. Clearly, the lower labor costs in country $F$ are the main motivation for firm $H$ to move parts of the production of country $F$ and it is therefore important to understand how the economic dynamics is influenced by the amount of the wage disparity. As discussed above we assume that wages stay constant over time, for example due to institutional inertia.

In order to examine the effects of an increase in $w_{F}$, we first consider the direct effect of such a parameter change on the equilibrium feedback functions of both firms. We carry out this analysis for a positive value of $\beta_{F}=0.2$ where in general no full technological catch-up of firm $F$ occurs. In Figure 5 we depict the change in the feedback functions as the wage in country $F$ increases by $10 \%$, i.e. we depict $\Delta I^{*}\left(K_{F}, A_{F}\right)=I^{*}\left(K_{f}, A_{F} ; w_{f}=1.1\right)-I^{*}\left(K_{f}, A_{F} ; w_{f}=1\right)$ and $\Delta \alpha^{*}\left(K_{F}, A_{F}\right)=\alpha^{*}\left(K_{f}, A_{F} ; w_{f}=1.1\right)-\alpha^{*}\left(K_{f}, A_{F} ; w_{f}=1\right)$. The figure clearly shows that a wage increase in country $F$ induces a downward shift of the foreign investment function of firm $H$ and an upward shift of the feedback function determining the absorptive effort of firm $F$, thereby enlarging the area in the state space where firm $F$ chooses positive effort. There is a clear intuition for these shifts. An increase of $w_{F}$ induces higher unit costs of labor for firm $F$, which increases its incentives to increase labor productivity and this leads to higher absorptive effort of that firm. This increase in absorptive effort reduces the incentives for firm $H$ to invest in country $F$. Furthermore, the increased wage costs in country $F$ reduces the cost savings of firm $H$ from production in country $F$, which also negatively affects its incentives for foreign investment.

The effects of these changes in the feedback functions on the equilibrium dynamics of states and controls can be seen in Figure 6. As expected, foreign investment the size of the foreign capital stock of firm $H$ becomes smaller throughout the run and in the steady state if the wage $w_{F}$ goes up. More surprisingly, the increase in wages in country $F$ induces a decrease in the productivity of firm $F$ throughout the run and in the steady state. This effect is particularly strong in the initial phase of the dynamics, where first the delay till the catch-up of firm $F$ starts becomes larger for increasing $w_{F}$ and then the speed of the catch-up is substantially smaller under a larger value $w_{F}$. Hence, although the incentives for firm $F$ to improve its labor productivity become stronger if the local wage goes up, in equilibrium the induced slowdown in the foreign investment is so strong that the actual productivity trajec- 


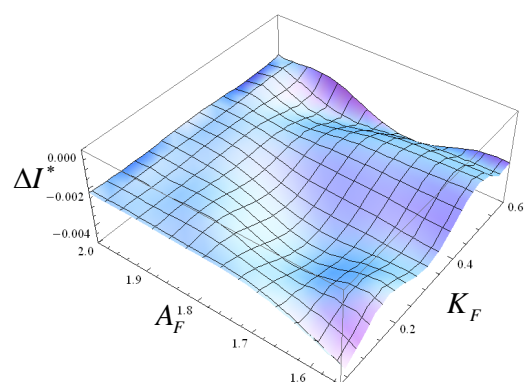

(a)

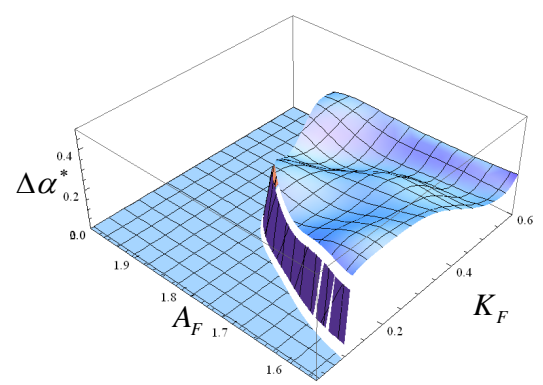

(b)

Fig. 5 Difference in the equilibrium strategies of firms $H$ (a) and firm $F$ (b) between the cases $w_{F}=1.1$ and $w_{F}=1$.

tory is shifted downwards. In the initial periods the reduction in foreign capital stock due to a wage increase implies even a reduction of absorptive effort of firm $F$.



(a)

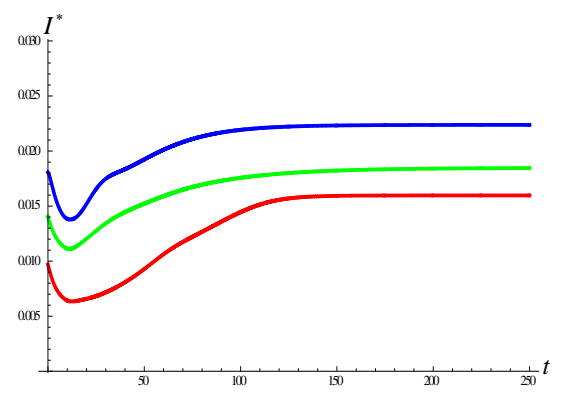

(c)

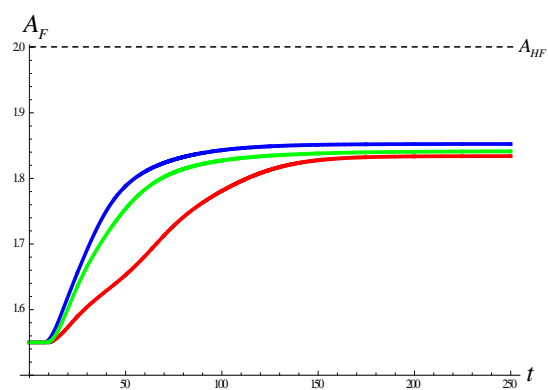

(b)

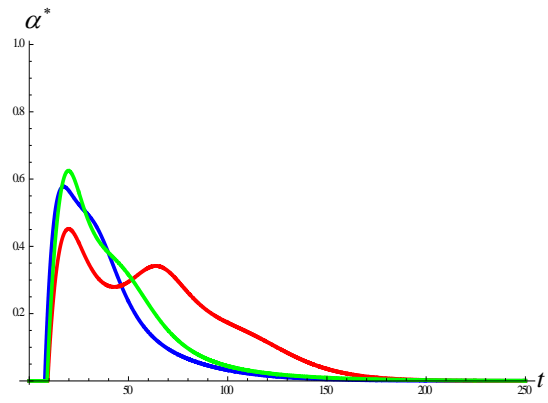

(d)

Fig. 6 Equilibrium dynamics for $w_{F}=1$ (blue line), $w_{F}=1.1$ (green line) and $w_{F}=1.2$ (red line): (a) foreign capital stock of firm $H$, (b) productivity of firm $F$, (c) investment of firm $H$, (d) absorptive effort of firm $F$. 
Based on these considerations, it is straight forward to see that the profits of firm $F$ are negatively affected by an increase of the local wage $w_{F}$. Numerical results not shown here confirm that an increase in $w_{F}$ induces a downward shift of the value function of firm $F$ and also a downward shift of the trajectory of instantaneous profits of that firm, which means that an increase of $w_{F}$ (for given initial conditions) implies not only lower productivity but also a reduction of profits of the firm at each point in time. Furthermore, numerical evidence shows that the total wage income of workers in country $F$ is positively affected by an increase of $w_{F}$, but that this effect is smaller than the induced loss of firm profits, such that total income in country $F$, consisting of the sum of firm profits and wage income, is negatively affected by the increase in $w_{F}$.

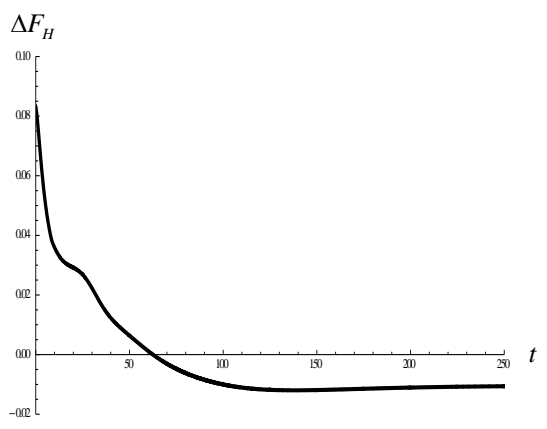

(a)

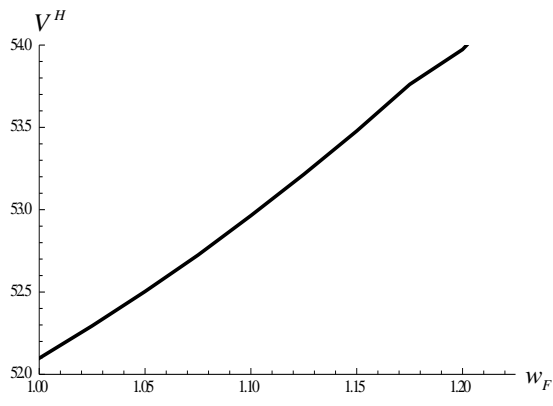

(b)

Fig. 7 Effects of changes in $w_{F}$ on the profit of firm $H$. (a) Difference in the instantaneous profits of firms $H$ between the cases $w_{F}=1.1$ and $w_{F}=1$; (b) value function of firm $H$ for the default initial conditions and an increasing value of $w_{F}$.

The effect of an increase in the wage in country $F$ on the profit of firm $H$ is less clear. On the one hand, such a wage increase makes the production of firm $H$ in country $F$ more expensive. Also, as discussed above, the wage increase leads to an upward shift of the absorptive effort of firm $F$. Both of these effects have negative implications for the profits of firm $H$. On the other hand, the wage increase induces higher marginal costs for the opponent firm $F$, which makes it a weaker competitor and induces an upward shift of the price. This increases the profit of firm $H$. As can be seen in panel (a) of Figure 7 the interplay of these effects with the adjustment of the optimal strategy of firm $H$ is such that an increase in $w_{F}$ initially leads to a higher profit of firm $H$ but induces a decrease in the long run profit. The main mechanism for these dynamic implications seems to be the induced reduction of investments of firm $H$ we discussed above. This reduction of investments which, does not only reduce investment costs but also leads to a substantial slowdown of initial technological catch-up of firm $F$, has particularly strong positive profit implication for firm $H$ in the initial periods, whereas the negative implications of an increase of $w_{F}$ grow over time as firm $H$ accumulates more foreign capital. Also, in the long 
run the increase in the technological gap $A_{H F}-A_{F}$ induced by the wage increase is much smaller than in the initial periods. However, as can be seen from panel (b) where the value function of firm $H$ is depicted for increasing values of $w_{H}$, the initial positive effect outweighs the negative long-run implications of the wage increase, such that the discounted payoff stream of firm $H$ in equilibrium increases with $w_{H}$.

Having examined the implications of a wage increase in country $F$, we conclude our analysis by briefly considering a scenario where even without any absorptive effort of firm $F$ this firm receives technological spillovers as long as firm $H$ has a positive capital stock in country $F$. With respect to our parametrization this means that we consider the implications of an increase of the parameter $a$ to some positive value. Figure 8 show the equilibrium dynamics of states and controls for $a=0$, $a=0.1$ and $a=0.2$. Whereas the difference in the dynamics between the cases with positive values of $a$ is very minor, there is a substantial difference between these two cases and our default setting where $a=0$. For positive values of $a$, firm $F$ always achieves a complete technological catch-up to $A_{F}=A_{H F}$. However absorptive effort of the firm is reduced to zero such that the catch-up is due to the 'automatic spillovers' generated by the positive capital stock of firm $H$. Firm $H$ could prevent such spillovers only by reducing its foreign capital stock to zero, but, as can be seen in panels (a) and (c) of the figure, the increase of the spillover intensity induces higher foreign investment of firm $H$ and also a larger foreign capital stock for almost the entire time interval. Intuitively, there are two reasons for this. First, the faster catch-up of $A_{F}$ towards $A_{H F}$ reduces the marginal effect of an additional unit of foreign capital on the future dynamics of $A_{F}$, and, second, since absorptive effort is constant zero for positive values of $a$, the strategic effect that an increase in the foreign capital stock of firm $H$ induces higher absorptive effort by firm $F$ is not present for positive values of $a$ and this increases the incentives of the firm for foreign investment.

\section{Conclusions}

In this paper, we have considered the dynamic strategic interaction between two competing firms located in a high- respectively low-tech country. The firm in the high-tech country can reduce production costs by moving parts of its production to the low-tech country, but by doing so risks to generate technological spillovers which allow its competitor to reduce the technological gap between the two firms in terms of productivity. Taking into account the literature on absorptive capacity we assume that the intensity of the spillovers does not only depend on the size of the foreign capital stock of the high-tech firm and the size of the technological gap, but also on the amount of effort invested by the firm in the low-tech country to absorb the spillovers. The differential game, which captures the strategic interaction between the two firms, is of highly non-linear structure and does not fall into any of the classes of games where analytical treatments of Markov Perfect Equilibria are 




(a)



(c)



(b)



(d)

Fig. 8 Equilibrium dynamics for $a=0$ (blue line), $a=0.1$ (green line) and $a=0.2$ (red line): (a) foreign capital stock of firm $H$, (b) productivity of firm $F$, (c) investment of firm $H$, (d) absorptive effort of firm $F$.

feasible. Therefore numerical methods of collocation type were used to examine the characteristics of the Markov Perfect Equilibria of the game.

Several noteworthy findings result from this numerical analysis. First, it is demonstrated that under weak assumptions on the cost function of effort equilibrium behavior leads to a steady state where the high-tech firm keeps a positive capital stock in the low tech country, but the productivity of the firm located in that country still does not catch-up to the productivity of the high-tech firm. Such a steady state is ruled out in the treatment of Dawid et al. [4], where the absorptive capacity of the local firm was assumed to be exogenously given. Second, the analysis highlights several interesting implications of changes in the key parameters on the equilibrium dynamics. In particular, it is shown an increase of the costs of absorptive effort of the low-tech firm leads to a reduction of the foreign investment of the high-tech firm in the initial part of the dynamics. An increase of the wage rate in the low-tech country induces a slower catch-up of the productivity of the firm in that country and less foreign investment of the high-tech firm. Finally, an increase of the base value (with zero effort) of the absorptive capacity of the low-tech firm to a positive value induces more foreign investment. Overall, this analysis demonstrates that even in games with more than one state and highly non-linear state dynamics the applica- 
tion of numerical collocation methods allows to obtain a clear and comprehensive picture of the qualitative properties of Markov Perfect Equilibria of the game.

\section{References}

1. Cohen, W.M. and D.A. Levinthal (1990), Absorptive Capacity: A New Perspective on Learning and Innovation, Administrative Science Quarterly, Vol. 35, 128-152.

2. Dockner E., S. Jorgensen, N. Van Long and G. Sorger (2000), Differential Games in Economics and Management Science. Cambridge University Press.

3. Das, S. (1987), Externalities, and technology transfer through multinational corporations: A theoretical analysis, Journal of International Economics, Vol. 22, 171-82.

4. Dawid, H., A. Greiner and B. Zou (2010), Foreign direct investment under international competition : Control of Spillover?, Journal of Economic Dynamics and Control, Vol. 34(3), 296-313.

5. Dockner E. and G. Mosburger (2007), Capital accumulation, asset values and imperfect product market competition, Journal of Differential Equations and Applications, V01. 13, 197-215.

6. , Doraszelski, U. (2003), An R\&D race with knowledge accumulation Rand Journal of Economics, Vol. 34, 19-41.

7. Fan E. (2002), Technological spillover from foreign direct investment-A survey, ERD Working Paper Series 33, Asian Development Bank.

8. Findlay R. (1978a), Relative backwardness direct foreign investment and the transfer of technology: A simple dynamic model, Quarterly Journal of Economics, Vol. 92, 1-16.

9. Javorcik B. (2004), Does Foreign Direct Investment Increase the Productivity of Domestic Firms? In Search of Spillovers Through Backward Linkages, Amercian Economic Review, Vol. 94(3), 605-627.

10. Jorgensen S. and G. Zaccour (2007), Developments in differential game theory and numerical methods: Economic and managemnet applications, Computational Management Science, Springer, vol. 4(2), 159-181.

11. Görg, H. and D. Greenaway (2004), Much ado about nothing? Do domestic firms really benefit from foreign direct investment World Bank Research Observer, Vol. 19, 171-197.

12. Gorodnichenko, Y., Svejnar, J. and K. Terell (2007), When Does FDI Have Positive Spillovers? Evidence from 17 Emerging Market Economics, IZA Discussion Paper No. 3079.

13. Halpern, L. and B. Murakozy (2007), Does Distance Matter in Spillover?, Economics of Transition, Vol. 15, 781-805.

14. Judd, K. (1998), Numerical mthods in Economics, Cambridge: MIT Press.

15. Kokko, A. (1994), Technology, market characteristics, and spillovers, Journal of Development Economics Vol. 43, 279-293.

16. Liu, Zh. (2008), Foreign direct investmnet and technology spillover: Theory and edidence, Journal of Development Economics, Vol. 85, 176-193.

17. Miranda, M.J. and Fackler, P.L. (2002), Applied Computational Economics and Finance, Cambridge: MIT Press.

18. Saggi, K. (2002), Trade, foreign direct investment, and international technology transfer: A survey, The World Bank Policy Research Observer, Vol. 17, 191-235.

19. Smarzynska, B. and M. Spatareanu (2008), To Share or Not to Share: Does Local Participation Matter for Spillovers from Foreign Direct Investment?, Journal of Development Economics, Vol. 85, 194-217.

20. Vedenov D. and Miranda M. (2001), Numerical solution of dynamic oligopoly games with capital investmnet, Economic Theory, 18, 237-261.

21. Wang J.-Y. and M. Blomstrom (1992) Foreign investment and technology transfer: A simple model, European Economic Review, Vol. 36, 137-55. 
22. World Bank (2008), Technology diffusion in the developing world, Global Economic Prospects 2008 . 